\title{
Conhecimento técnico e atitude no ensino de língua portuguesa
}

\author{
Thomas Massao Fairchild
}

Universidade Federal do Pará

\section{Resumo}

Contra a ideia de que os conhecimentos técnicos do professor de língua materna sirvam prioritariamente ao conteúdo de seu ensino ou ao planejamento de suas aulas, neste artigo, discute-se o preceito de que tal conhecimento seja assumido também como base para a elaboração de uma atitude a ser mantida nas interações face a face da sala de aula. Essa atitude diz respeito à constante necessidade de tomar decisões diante do inesperado e aponta para a construção de um lugar discursivo específico do professor de língua - o de quem escuta a palavra do aluno e a enlaça à sua, de maneira a garantir que a assunção de um lugar de sujeito passe por uma reflexão sobre os meios linguísticos disponíveis para tanto. Toma-se como exemplo para esse debate a interpretação inusitada que alguns alunos fazem da palavra "rataria", presente num texto de Monteiro Lobato. Discutem-se certas atitudes que poderiam ser tomadas em relação a esse erro de leitura e suas implicações: requisitar a modificação da resposta, modificar o material didático, explicitar o trabalho linguístico subjacente ao erro ou utilizar o erro como pretexto para outras atividades. Os encaminhamentos discutidos fundamentam-se na premissa de que erros e outras manifestações imprevistas não apenas revelam procedimentos de construção do conhecimento, mas também oferecem oportunidades importantes para que o professor se faça incluir na palavra do aluno, sendo, portanto, um aspecto fundamental na construção de uma relação em que o ensino se torne possivel.

\section{Palavras-chave}

Ensino de língua portuguesa - Formação de professores - Leitura Sujeito contemporâneo.

\footnotetext{
Correspndência:

Thomas Massao Fairchild

Av. João Paulo II, 327, apto. 201

66095-490 - Belém - PA

e-mail: tmfairch@yahoo.com.br
} 


\title{
Technical knowledge and attitude in the teaching of Portuguese language
}

Thomas Massao Fairchild

Universidade Federal do Pará

\begin{abstract}
Contrary to the idea that the technical knowledge of the teacher of a native tongue serves primordially to the content of its teaching or to the planning of classes, this article discusses the precept that such knowledge should be seen as the basis for the creation of an attitude to be maintained in face-to-face interactions in the classroom. This attitude relates to the constant need to make decisions before the unexpected, and points to the construction of a specific discursive place for the language teacher - that of someone who listens to the student's words and enlaces them to his or her own words, so as to make sure that the assumption of the position of subject follows a reflection about the linguistic means available to such end. As an example to fuel this debate, the text describes the case of the unusual interpretation made by some students of the word "rataria" present in one of Monteiro Lobato's works. Some of the possible attitudes before this reading mistake are discussed, as well as their implications: to request a change in the answer, to modify the didactic material, to make explicit the linguistic work underlying the mistake, or to use the mistake as a pretext to other activities. The procedures discussed are based on the premise that mistakes and other unforeseen manifestations not only reveal procedures of construction of knowledge, but also offer important opportunities for the teacher to include him/herself into the student's word, being, therefore, a fundamental aspect in the construction of a relationship in which teaching becomes possible.
\end{abstract}

\section{Keywords}

Teaching of Portuguese language - Teacher education - Reading Contemporary subject.

Contact:

Thomas Massao Fairchild

Av. João Paulo II, 327, apto. 201

66095-490 - Belém - PA

e-mail: tmfairch@yahoo.com.br 
Tenho a convicção de que, se o conhecimento técnico de um campo é fundamental na maior parte das especialidades, talvez o mesmo não valha para o professor de língua materna. Mais que o saber técnico, um conjunto de atitudes derivadas dele talvez resulte em benefícios maiores [...]. (Possenti, 2004, p. 32)

Não devo estar sozinho quando afirmo que muitas concepções de caráter tecnicista são hoje largamente aceitas na formação do professor. Essa perspectiva manifesta na ideia de que o preparo para a docência deve anteceder a própria docência e dar-se num espaço separado para que, apenas em seguida, o professor seja autorizado a arriscar-se em sala de aula.

Costuma-se pensar que existe um campo da teoria que precede a prática e se mantém suspenso ao seu lado como uma nuvem, pairando ao sabor de suas próprias moções internas. Essa premissa leva a alguns receios bastante comuns, como o de enviar à escola um professor "despreparado" e causar um desastre que poderia ser evitado pelo prolongamento de seu preparo técnico anterior.

Concordo que há razões para esse tipo de preocupação, mas penso que essa perspectiva pode se tornar prejudicial se passar a legitimar o adiamento da prática docente ou sua excessiva amenização durante os estágios. Gostaria de contrapor a esse ponto de vista um problema que também considero importante: o da atitude que compõe, tanto quanto seu conhecimento técnico, o perfil do professor de língua portuguesa.

Parece-me que, quando se toma a profissão docente como um exercício estritamente ligado à técnica, há duas coisas que se consideram importantes em sua formação: a) a transmissão de um repertório de saberes que consistem na herança científica da área; e b) a preparação para a sala de aula. Duas articulações entre esses campos são frequentes: ou se pensa que a preparação para a sala de aula requer suas próprias técnicas, à parte do bacharelado, condensadas em disciplinas como a
Didática, ou se pensa que a simples excelência no primeiro campo bastaria para garantir o sucesso no segundo. Em um ou outro caso, os problemas do ensino de língua tendem a se perder num vão entre a Pedagogia e as Letras, e as disciplinas que tratam especificamente desse assunto (Estágio Supervisionado, Prática ou Metodologia do Ensino de Língua Portuguesa etc.) permanecem sem uma definição clara do seu papel. Um sintoma disso é que, não raro, acabam dominadas por questões de cunho prático e imediato - agendamento dos estágios, encorajamento emocional dos estudantes, preenchimento de fichas e por aí afora.

Pensar no problema das atitudes em sala de aula nos faz supor que as disciplinas ligadas ao ensino de língua possuem uma especificidade epistemológica, porque a natureza da linguagem como objeto de ensino é um ponto de partida importante para a elaboração das maneiras de se ensinar. 0 tipo de atitude que nos interessa discutir, dessa forma, não é uma postura qualquer questão missionária ou de boa vontade -, mas as formas de agir em sala de aula, que se enraízam nos conhecimentos da área de especialização do professor e no compromisso político que se inicia com a própria decisão de tornar-se professor.

$A$ atitude pode ser pensada, de certa forma, como o avesso da técnica. De uma parte, ela se refere ao que encontraríamos se observássemos um professor sem pressa ou compromisso de atribuir-lhe adjetivos abrangentes (tradicional ou inovador, autoritário ou libertário etc.), mas à medida que o significado desses adjetivos vai se reconstruindo com o tempo. Não se trata, contudo, de pensar na forma pessoal como o professor recebe cada nova circunstância de ensino o amor ou desdém com que abraça seu ofício, a meticulosidade que mostra em seu trabalho ou ainda a forma como se coloca perante os alunos: se fala alto ou baixo, se marca distância por meio de um vocabulário precioso ou busca comunicarse coloquialmente, se é rigoroso ou leniente, sisudo ou amigável etc.

A atitude terminaria se desenhando, como que por si só, como uma espécie de perfil 
ou, se quisermos, uma forma de "fazer com" nos termos de Michel de Certeau (1994). É a maneira como se aproveitam os aspectos técnicos do ensino, como as estruturas teóricas e regimentais comparecem nas decisões que o professor toma em seu cotidiano - por isso mesmo, uma forma de inventar esse cotidiano. Isso não significa pensar o professor necessariamente como um fraco que só pode atuar sob a dominação de um aparelho que o constringe, mas significa pensar que todo aspecto técnico do ensino, como terreno de antecipações estratégicas, está sujeito a um aproveitamento de cunho tático, que pode ser coerente e solidário aos princípios de sua organização estratégica ou pode estabelecer, em relação a eles, uma forma de subversão. Isso sugere, a respeito do modelo polemológico de Certeau, que estratégias e táticas nem sempre representam um conflito entre posições antagônicas: toda estratégia, mesmo dotada de seus agentes convictos, depende de um "fazer com" para tornar-se vigente. 0 trabalho dos poderosos ou dos empoderados não poderia contar, mais do que o dos fracos, com uma transparência que os tornasse reais, para si mesmos, tão logo fossem concretizados em suas arquiteturas e seus decretos: um poder só é poder porque pode contar com algo mais do que um lugar próprio.

0 problema da atitude, dessa forma, é o de considerar em que medida a experiência da sala de aula se caracteriza como uma forma de evasão ou de implementação. 1sso, em todo caso, não interessa para a finalidade de denunciar o problema dos "discursos que não condizem com as práticas”, porque o percurso que nos interessa não é o que levaria o professor a desviar-se de uma postura declarada, mas o que o levaria a estar de acordo com ela.

De outra parte, a atitude se revela em acontecimentos miúdos, nos episódios inusitados, nas surpresas do dia a dia. É um saber anedótico, muitas vezes sem sistematização. Bastaria observar o professor em um momento de improviso: o que nos interessa é a resposta encontrada na única oportunidade que se tem de responder a uma questão que não se repetirá. Se a técnica é uma aposta na possibilidade de prever, a atitude é então a maneira de lidar com o inesperado, o imprevisto.

Falar na atitude do professor importa porque ela recobre os intervalos que toda técnica forçosamente deixa a descoberto: ela é o único artifício de que dispomos para lidar com o inabarcável do cotidiano, com os desafios da prática. Vale a pena assumir o risco de afirmar que é por meio de atitudes, e não de técnicas, que um conhecimento tem qualquer possibilidade de transmitir-se, de passar adiante ao se escrever na relação entre o professor e o aluno. Falar em atitudes é, portanto, falar da maneira como se resolvem esses episódios esporádicos que pontuam o cotidiano da sala de aula, nos quais as demandas dos sujeitos ganham expressão na forma de perguntas deslocadas, erros surpreendentes, esquecimentos, repetições etc. É especificamente desse tipo de questão que gostaria de tratar neste texto.

Falar na atitude do professor importa, ainda, porque não cessam de encontrar sustentação os discursos que apostam numa determinada técnica, método ou material didático como eixo articulador de viradas qualitativas no ensino, enquanto pouco ou nada se fala sobre o professor para além de suas adesões ou rejeições em relação a essas técnicas, métodos ou materiais. Essa questão aparece de forma muito sensível, por exemplo, em terrenos como a alfabetização, historicamente marcada pelas querelas entre propositores de diferentes métodos de ensino (Mortatti, 2000; Belintane, 2006), em políticas de formação continuada calcadas numa noção geral de capacitação ou atualização teórica e numa certa leitura normativizante dos PCN, senão ao menos de alguns termos neles presentes (como o conceito de gêneros discursivos).

Enfim, importa pensar na atitude porque é preciso responder a uma pergunta que sempre nos confronta - o que estamos propondo para a escola ao criticar certas formas do chamado ensino tradicional? Parto do princípio de que o professor de Língua Portuguesa tem à 
sua disposição um repertório teórico que não serve apenas para o planejamento estratégico de seu ensino, mas também lhe dá respaldo quando se trata de lidar taticamente com o imprevisto. Parece-me razoável afirmar que, para além do conhecimento de certo cabedal teórico, o professor de língua precisa elaborar certo tipo de prontidão amparada no seu conhecimento sobre a linguagem. Passarei a discutir isso por meio de uma situação vivenciada durante a supervisão de estágios em um curso de graduação em Letras. Esse exemplo ilustra uma ocorrência imprevisível, mas bastante mundana, e mostra a necessidade de uma atitude como solução para certos impasses do ensino. Como veremos, tomar uma atitude requer a incursão no domínio de um conhecimento técnico, de modo que não há forma de subtrair um termo do outro. As medidas discutidas abaixo, de certa forma, apresentam-se numa progressão e vão ilustrando, de maneira genérica, diferentes posturas didáticas. Antes de tudo, eis o caso.

\section{Em algum lugar numa casa velha...}

Um estagiário leva aos alunos um texto de Monteiro Lobato e propõe um conjunto de questões de interpretação. Do ponto de vista do planejamento técnico, trata-se, sem dúvida, de uma aula que poderíamos contestar. 0 texto e as perguntas provêm de um livro didático - o que indica que a escolha da leitura provavelmente não se pauta num levantamento sobre o interesse dos alunos e talvez nem mesmo numa proposta particular do estagiário, mas apenas no critério da disponibilidade de material pronto. Poderíamos iniciar uma discussão sobre as maneiras de repensar essa aula do ponto de vista da escolha do material, da forma de trabalho com a leitura, das concepções de texto aí implícitas etc. Ainda assim, isso levaria ao equívoco de supor que uma aula poderia estar pronta em algum momento que não no da sua própria realização, atravessada por impasses que não podemos evitar, senão apenas confron- tar. Em todo caso, durante essa aula acontece um episódio relevante, que não poderia passar despercebido pelo professor, porque exige a tomada de uma decisão instantânea. Há um trecho do texto que diz o seguinte:

Um gato de nome Faro-Fino deu de fazer tal destroço na rataria duma casa velha que os sobreviventes, sem ânimo de sair das tocas, estavam a ponto de morrer de fome. (extraído de "Assembleia dos ratos", de Monteiro Lobato).

Um pouco mais adiante, entre as perguntas sobre o texto, consta a que reproduzo a seguir, respondida por um bom número de alunos desta maneira:

Em que ambiente viviam os ratos?

R.: Na rataria duma casa velha

0 exercício que proponho é o de considerar algumas ações que poderíamos tomar a partir dessa ocorrência, levando em consideração os postulados teóricos que estaríamos pressupondo em cada caso e suas consequências em termos de ensino.

Um primeiro problema a se considerar, logo de partida, como vemos, é a própria possibilidade de a ocorrência não ser percebida, seja porque não acompanhamos o trabalho dos alunos com atenção o suficiente, seja porque estamos interessados apenas nas respostas que consideramos corretas. 0 simples recorte dessa ocorrência como dado relevante, portanto, já decorre de uma atitude em sala de aula: se nos limitamos a corrigir exercícios em voz alta e não damos ouvidos aos erros dos alunos, uma questão suscitada pela leitura do texto pode passar despercebida e, para os alunos, permanecerá em aberto.

Isso mostra a importância de saber discernir a que um professor de língua deve estar atento durante a aula e onde pode procurar indícios que revelem um trabalho pertinente à sua disciplina nesse caso, um trabalho com a língua. Apresentar 
uma ocorrência dessa natureza a estudantes de estágio pode ter a vantagem de exemplificar o tipo de dado que eles devem estar prontos para coletar e discutir em sua prática docente.

Mais do que perceber esse impasse na leitura do texto como um fato importante, em todo caso, seria importante encontrar algumas saídas imediatas para aquilo que a resposta dos alunos coloca em questão, evitando retomar o assunto tardiamente, depois que as próprias motivações dos alunos, e talvez a relevância de se discutir o tema, já tenham se perdido. Eis agora algumas possibilidades.

\section{Considerar a resposta errada e requisitar sua modificação}

Essa decisão coloca em jogo alguns pressupostos sobre a natureza da leitura e, talvez, sobre os limites da participação do leitor na atribuição de sentido ao texto. Um primeiro ponto importante é certificar-se que a resposta dos alunos não poderia ser considerada correta sob nenhuma perspectiva. Isto é: não há como supor que a palavra "rataria", na fábula de Monteiro Lobato, refira-se a uma parte da casa. Essa interpretação não se justifica nem em relação ao gênero (não há nenhum ganho interpretativo em se supor que o autor faça um jogo de palavras aí) nem em relação ao restante do texto (não há retomadas desse elemento que confirmem a interpretação) ${ }^{1}$. Dessa forma, se formos levar a sério o exercício proposto, seria inevitável rejeitar a resposta dos alunos e pedir que a reformulem.

0 fato de a leitura dos alunos não se sustentar como interpretação possível desse texto, no entanto, não significa que não seja uma leitura. Mesmo que tenhamos de rejeitá-la dentro do contexto específico do exercício que foi proposto, podemos considerar o que ela mostra a respeito do próprio exercício. Veremos assim que o erro dos alunos aponta para uma característica do texto escolhido: o fato de que há uma dificuldade de leitura no primeiro parágrafo, motivada por uma peculiaridade estilística ou pela distância do leitor contemporâneo em relação a certos usos da língua adotados pelo autor. Essa dificuldade está prevista no próprio material didático, mas de forma insuficiente - o exercício inclui um pequeno glossário com sinônimos para palavras consideradas difíceis como "destroço", mas não faz qualquer comentário sobre "rataria”. Se considerarmos o erro dos alunos como um indicativo disso, pelo menos duas perspectivas de trabalho com a leitura surgirão em nosso horizonte: as questões referentes ao estilo e à mudança linguística, que poderiam ser amarradas a um estudo do texto literário ou da obra de Monteiro Lobato, conforme sejam os objetivos.

Essa forma de consideração do erro sugere também que respostas erradas são tão importantes quanto respostas certas, mesmo que não lhes reservemos um tratamento igual, porque revelam como o texto foi lido e como atua determinado leitor. Sugere ainda que o trabalho do professor não cessa com a constatação dos erros dos alunos, e que corrigi-los pode não ser um tratamento suficiente para as questões que eles levantam. No presente caso, basta notar que, se apenas retificássemos as respostas de uma turma, o mesmo problema provavelmente se repetira em outras ocasiões sem que os alunos tirassem qualquer proveito da provocação contida no termo "rataria" - vale dizer, sem que o impasse com essa palavra os levasse a qualquer novo conhecimento sobre as causas linguísticas do impasse (o processo de formação da palavra, as circunstâncias do seu uso, seu valor específico dentro desse texto etc.). Seria viável, portanto, supor que a atitude do professor diz respeito a uma forma de produzir a partir dos percalços que surgem no decurso da aula.

\section{Modificar o material didático utilizado na aula}

Se não quisermos nos limitar a constatar o erro dos alunos, a medida mais simples tal-

1. Sírio Possenti (1999) assina um artigo sobre a questão da leitura errada ao qual o exemplo que estamos discutindo poderia se somar. 
vez seja modificar o material usado na aula. Uma forma de fazer isso seria incluindo a palavra "rataria" no glossário ao fim do texto. A apresentação de listas desse tipo parece partir do pressuposto de que uma leitura boa é aquela que acontece de forma mais rápida e direta, de modo que palavras desconhecidas e equívocos seriam um obstáculo no processo de ler e não uma parte constitutiva da leitura. Se concordarmos com isso, ao modificar o glossário, estaremos evitando que o mesmo tipo de embaraço ocorra desnecessariamente no futuro.

Essa solução tem vantagens e desvantagens. Uma das vantagens é o fato de que o professor estaria assumindo certa postura autoral em relação ao material que utiliza, mesmo que este tenha sido originalmente copiado de um livro ou apostila (como é o caso). Trata-se de uma forma incipiente de produção que pode ser o ponto de partida para investidas de maior fôlego (como a seleção de textos ou a elaboração de atividades para dar sequência ao exercício etc.). Seria preciso considerar, então, que o fato de o professor escrever material para sua disciplina não se contrapõe ao uso de materiais comerciais, mas de fato talvez seja a única condição em que esse uso pode se tornar legítimo, na medida em que não resulte da falta de alternativas.

Outro aspecto relevante é o fato de que acrescentar "rataria" ao glossário implica, ao menos por um instante, atribuir à palavra do aluno uma importância maior do que ao material didático. Significa, portanto, dar-lhe ouvidos mesmo quando o que ele diz não é o que esperávamos que dissesse e deixar-nos surpreender pelo que a sua leitura, ainda que errada, acrescenta à nossa própria leitura (nesse caso, mostrando que há uma questão de leitura a ser tratada no primeiro parágrafo da fábula que nem o professor nem o autor do livro didático previram). Esse é um ponto bastante sensível, porque muitas vezes a postura em sala de aula é tal que nem sequer esse tipo de ajuste é realizado, e o mesmo problema acaba se repetindo diversas vezes sem levar a lugar algum.
Disso podemos concluir que a prontidão do professor depende da sua segurança para contestar a autoridade de materiais publicados quando uma situação prática os surpreende.

Outra forma de modificar o material, ainda com a mesma finalidade, consistiria em reescrever o primeiro parágrafo do texto, evitando a palavra "rataria" (e, se for o caso, também "destroço"). Essa talvez não seja a melhor solução nesse caso, mas poderia ser em outros. Chegaríamos a algo como:

Um gato de nome Faro-Fino deu de fazer tal estrago entre os ratos duma casa velha que os sobreviventes, sem ânimo de sair das tocas, estavam a ponto de morrer de fome.

Embora exista hoje certa noção de que o trabalho com excertos ou adaptações seja uma forma de depauperar a integridade do texto original, essa solução não parece trazer grandes prejuízos, levando-se em consideração o que o exercício pede ao aluno - situar no texto uma informação sobre o espaço da narrativa. Sob essa luz, de fato, ela não é menos justificável do que incluir ao fim do texto um pequeno glossário. Evidentemente a questão seria outra se o que estivesse em estudo fosse a obra de Monteiro Lobato, seu tratamento estilístico da linguagem ou a comparação entre textos para crianças escritos na primeira metade do século passado e os livros infantis contemporâneos.

Essa solução é particularmente relevante como exercício para o professor em formação, já que, em último caso, é melhor saber como adaptar textos aos alunos ou aos propósitos específicos de uma determinada aula do que depender da existência de adaptações prontas. Realizar esse tipo de intervenção, sabendo pesar suas consequências, pode ampliar bastante um leque de escolhas, evitando que um bom texto seja descartado por conta de miudezas. Ademais, não há razão para recear que o professor esteja menos pronto para adaptar textos a alunos do que qualquer outro profissional e, se ainda assim o receio for em relação ao 
próprio uso de textos adaptados, seria preciso lembrar que, no limite, seria impossível considerar qualquer texto como uma aparição absolutamente original, sem considerar a espessura parafrástica que compõe todo enunciado. Evidentemente, adaptar textos não é uma ação indiferente nem suplanta a função da leitura do texto original. No entanto, seria possivel estabelecer alguns parâmetros para o trabalho de adaptação em relação à função do texto no ensino e ao seu gênero: modificar a diagramação ou suporte, por exemplo, é uma forma de adaptação amplamente aceita e pouco percebida como tal. Outros recursos seriam suprimir trechos para abreviar o tempo de leitura ou o espaço ocupado pelo texto, substituir termos técnicos ou de jargões específicos por termos mais gerais, acrescentar comentários (nisso se incluindo os glossários, mas também as ilustrações e, quem sabe, o próprio ato de justapor a um texto outro que se considera afim, por forma ou conteúdo) etc.

Em contrapartida, é preciso lembrar que essas soluções têm um problema em comum o fato de retirarem do texto justamente um ponto em que ele instiga a reflexão linguística do aluno. Ao realizar essas modificações, seja ampliando o glossário ou tornando-o desnecessário pela modificação do texto, resta implícito o preceito de que uma boa leitura seria uma leitura sem surpresas, na qual as interpretações programadas pelo professor ou previstas pelo material acabam prevalecendo sobre as do aluno - tanto que buscamos interromper toda divergência antes mesmo que surja. 0 maior embaraço talvez não seja o caráter monológico dessa premissa, mas o fato de se tratar de um esforço vão, já que as leituras alheias, mesmo que delicadamente cerceadas, dificilmente cessarão de nos surpreender.

Uma linha de trabalho diferente nos levaria a manter o texto tal como está, não exatamente em nome de sua integridade ou por receio de intervir em um cânon, mas por assumir que o equívoco faz parte da leitura e que, portanto, mais do que evitá-lo, cabe encontrar formas de trabalhar a partir dele. Em certa medida, essa perspectiva nos faria negar o próprio exercício a partir do qual vimos refletindo, já que questões de interpretação dessa natureza buscam antes de tudo esquematizar a leitura e livrá-la das ambiguidades. Por ora, no entanto, pensemos apenas em como poderíamos nos engajar com a palavra do aluno uma vez que as coisas tenham se passado tal como se passaram.

\section{Explicitar, do ponto de vista linguístico, o processo que origina o erro}

Essa postura tem como ganho o fato de descartar a noção de erro como deficit, já que nos faz pensar não no que o aluno deixou de fazer, mas no que teve de fazer para errar exatamente como errou. Fazer isso pode não ser muito cômodo, já que exige abandonar o terreno dos exemplos previamente elaborados e posicionar-se sobre um material que é sempre inédito - a produção dos alunos. É verdade, então, que frequentemente encontraremos ocorrências que nos intrigam, sobre cujos processos de produção pouco saberíamos dizer, ao menos em um primeiro momento - teríamos aí um largo campo de estudos em torno de questões como a aquisição da escrita (Abaurre; Fiad; Mayrink-Sabinson, 1997), a singularidade e a constituição do sujeito ou o problema do estilo e da autoria (Possenti, 1988). Este, contudo, não é o caso da palavra "rataria" nem de muitos outros erros similares, porque o que está em jogo, pelo menos à primeira vista, não é um dado único nem um lapso, mas uma peculiaridade da língua.

Comecemos percebendo que os alunos respondem à questão de maneira incorreta não apenas porque desconhecem a palavra "rataria", mas sobretudo porque, ao se depararem com uma palavra desconhecida, dispõem de uma série de estratégias para inferir seu significado. Nesse caso, parece que a estratégia central consiste na análise morfossintática da palavra "rataria", mas ao realizá-la, alguns alunos acabam sendo conduzidos a um engano, que resulta da com- 
binação de dois fatores: a) o fato de essa palavra ser formada por um processo não muito produtivo na língua portuguesa (a formação de substantivos coletivos com o sufixo -aria ou -ia); e b) o fato de o produto desse processo poder ambiguizar-se com o de outro processo mais produtivo (a formação de substantivos que designam continentes a partir de conteúdos, especialmente no caso específico de nomes de estabelecimentos comerciais, com o sufixo -aria).

Podemos supor, portanto, que a interpretação da palavra "rataria" como termo que designa um espaço da casa decorre da associação dessa palavra a um conjunto de outros termos de estrutura semelhante, que poderiam ocorrer na mesma posição dentro da estrutura sintagmática da oração - pizzaria, malharia, confeitaria etc. A partir da comparação entre os vocábulos desse paradigma, os alunos parecem inferir, até aqui corretamente, a possibilidade de segmentá-los em dois elementos menores, sendo um deles o radical e outro, o sufixo -aria:

$$
\begin{aligned}
& \text { Rat -aria } \\
& \text { Pizz -aria } \\
& \text { Malh -aria } \\
& \text { Confeit -aria }
\end{aligned}
$$

Podemos supor que os alunos atribuem ao sufixo -aria um significado comum, que deve ser mais ou menos o de "estabelecimento (ou cômodo) onde se encontram muitos x", sendo $x$ correspondente ao significado do elemento radical. Sem saber o que possa ser uma "rataria", eles reconhecem a palavra "rato" na raiz do novo vocábulo e chegam à hipótese de que deve se tratar de um "lugar onde há muitos ratos" ou talvez um "lugar onde se armazenam ratos".

Uma maneira de tornar isso explícito aos alunos seria requisitando-lhes que levantassem 0 maior número possível de palavras semelhantes a “rataria”. É provável que obtivéssemos tanto termos da ordem de padaria, sorveteria, cavalaria, gritaria etc. quanto da ordem de ratazana, ratoeira, ratinho, ratão etc. Isso bastaria para dar ensejo a uma dis- cussão sobre radicais e afixos e os aspectos combinatórios implicados na formação de palavras. Em todo caso, seria relevante levar adiante o exercício, pedindo que os alunos tentassem agrupar as palavras formadas com -aria, conforme os diferentes sentidos que o sufixo pode assumir. Chegaríamos a um resultando semelhante a este:

\begin{tabular}{|l|l|l|}
\hline \multicolumn{1}{|c|}{$\mathbf{1}$} & \multicolumn{1}{c|}{$\mathbf{2}$} & \multicolumn{1}{c|}{$\mathbf{3}$} \\
\hline Rataria & Rataria (?) & Correria \\
\hline Cavalaria & Sorveteria & Gritaria \\
\hline Infantaria & Pizzaria & \\
\hline & Danceteria & \\
\hline & Lancheteria & \\
\hline
\end{tabular}

No grupo 1, estão palavras com o significado geral de "um grupo de x". No grupo 2, estão palavras com o sentido de "lugar em que se vendem/armazenam/encontram x". Num terceiro grupo, palavras com uma terminação semelhante que significam "muitas pessoas fazendo x simultânea e desordenadamente”.

Se quiséssemos refinar o exercício, poderíamos observar que, aparentemente, as palavras do grupo 1 são de composição diferente das do grupo 2: enquanto ali o sufixo parece ser -aria, aqui é difícil dizer se há uma alternância entre duas formas, -eria e -aria, ou se se trata de um único sufixo -ria que se agrega ao radical sem causar a síncope da vogal temática. Dentro do grupo 2, há ainda um subconjunto de palavras cuja formação ocorre com uma forma -eteria, possivelmente em paralelo com o termo "sorveteria" e a partir de uma reinter-pretação do radical sorv(em analogia com o verbo sorver).

\begin{tabular}{|ll|}
\hline \multicolumn{1}{|c|}{1} & \multicolumn{1}{c|}{2} \\
\hline Caval(o) - aria & Sorvet(e) -eria / Sorvete -ria \\
\hline Infant(e) - aria & Pizz(a) -aria / Pizza -ria \\
\hline & (Sorv(?) -eteria) \\
\hline & Danc(a) -eteria \\
\hline & Lanch(e) -eteria \\
\hline
\end{tabular}

Enfim, também poderíamos chamar a atenção para o fato de que os radicais das palavras dos grupos 1 e 2 são substantivos, ao passo que o grupo 3 é formado com bases ver- 
bais. Isso colocaria em jogo diversas possibilidades de decompor morfologicamente aqueles termos:

\begin{tabular}{|l|l|l|}
\hline Grit(o) - aria & Grita - ria & Gritar - ia \\
\hline Corr(o) - eria & Corre - ria & Correr - ia \\
\hline
\end{tabular}

Essa provavelmente não será a maneira como encontraremos o assunto tratado em manuais de gramática, e nada impede que as hipóteses levantadas pelos alunos sejam cotejadas com outras formas de análise morfológica. A guisa de exemplo, a gramática de Cunha e Cintra (1985, p. 94) menciona apenas dois sufixos, -aria e -ia. Cita como exemplos de -aria, dentre outros, carpintaria ("atividade, ramo de negócio"), gritaria ("noção coletiva”) e pirataria ("ação própria de certos indivíduos”). Como exemplos do sufixo -ia, levanta, dentre outros, advocacia ("profissão, titulatura"), delegacia ("lugar onde se exerce uma atividade") e cavalaria ("noção coletiva").

Do ponto de vista desse tipo de trabaIho, é menos importante chegar a uma análise definitiva do que passar por alguns processos de análise válidos para chegar a algumas conclusões possíveis, ainda que provisórias, sobre uma questão linguística que em dado momento se tornou relevante. É uma questão de atitude assumir que o conhecimento sobre a língua (inclusive o nosso) está incompleto, dar prevalência à descrição da língua sobre a normatização do seu uso e levar em consideração a palavra do aluno mesmo quando o que ele diz não é o que o esperávamos. No entanto, trata-se de uma atitude que não poderia tomar forma concreta se não estivéssemos minimamente amparados para fazer uma análise do material apresentado pelo aluno. A partir daqui, poderíamos chegar a uma conclusão importante: certas atitudes do professor dependem de sua segurança para chegar a conclusões sobre dados a respeito dos quais não há uma análise consolidada.

Entretanto, uma última linha de ação ainda nos levaria em um caminho diferente.

\section{Utilizar o erro como pretexto para outras atividades}

Se até agora nos concentramos sobre a dimensão formal do erro cometido por alguns alunos, talvez seja oportuno atentar para sua dimensão interacional: o fato de que na resposta errada não há somente uma análise morfossintática implícita, mas também uma aposta na possibilidade de tapear o professor, isto é, uma tentativa de acertar o exercício mesmo sem se saber a resposta certa.

Numa hipótese otimista, suporemos que o aluno age assim de má fé - ele não leu o texto e sabe que não o leu ou não está disposto a levar o exercício a sério e, portanto, lança mão de um estratagema bem conhecido: copiar um fragmento onde parece estar embutida a resposta que o liberará da tarefa o mais rápido possível. Sabemos que isso muitas vezes é, em parte, um problema na formulação da própria pergunta. Em todo caso, o que há de otimista nisso é que, nesse caso, ainda podemos imaginar o aluno como alguém que agencia uma estratégia de escrita em prol de um objetivo interacional específico - o de burlar o professor. Numa perspectiva pessimista, por outro lado, teríamos de supor que o aluno talvez responda à pergunta dessa maneira porque não concebe outra forma de ler um texto ou resolver um exercício escolar - não leu o texto ou o leu de maneira precária, mas não tem uma medida suficiente da precariedade de sua leitura.

Penso em pelo menos duas formas como poderíamos desdobrar esse erro em atividades derivadas que fizessem o aluno retornar ao processo de produção do erro com novos olhares. Uma delas seria aproveitar-se dessa ocorrência para instigar um trabalho que canalizasse a criatividade intuitiva da análise aí implícita para algum propósito mais específico de escrita. Poderíamos começar apresentando-lhes o caso (como se tratou de um erro coletivo, não haveria razão para o receio de expor os alunos) e levantando questões que revolvessem o processo pragmático do erro e não sua faceta formal - o que é uma "rataria", de que mate- 
rial é feita, qual seria sua função dentro de uma casa, se há diferenças entre as ratarias de casas velhas e novas etc. Atividades bastante simples e produtivas poderiam se desenrolar daí por diante como propor aos alunos que descrevam uma "rataria" ou redijam um verbete enciclopédico (fantástico) definindo-a; que contem ou escrevam outras histórias passadas numa "rataria"; que elenquem outros compartimentos fabulosos similares e os descrevam e/ou ilustrem (gatarias, cachorrarias, passarinharias, pessoarias ou personarias etc.). Esses seriam exercícios nos moldes do "binômio fantástico" proposto por Rodari (1982) que, além de fazer com que o aluno se detenha sobre um processo construtivo da linguagem, acabariam propondo novas questões de textualidade - por exemplo, as formas de se explicar ou evidenciar o sentido de uma palavra desconhecida para o leitor, as formas de causar surpresa ou riso pela atribuição de um sentido inesperado a uma palavra etc.

Outro rumo seria utilizar o deslize contido na palavra "rataria" como ponto de partida para um trabalho que chame a atenção para processos similares que ocorrem em outros gêneros discursivos e seus efeitos interacionais. Seria o caso, por exemplo, de pesquisar a constituição das piadas baseadas em trocadilhos e dos chistes ${ }^{2}$. Há fontes abundantes para esse tipo de texto - a própria vida escolar é cenário de uma ampla circulação de piadas orais e o e-mail, um grande veículo de propagação de textos humorísticos escritos. Em todo caso, seria preciso atentar para o fato de que nem toda piada se baseia em procedimentos semelhantes ao da leitura de "rataria". À guisa de exemplo, dois tipos de piadas que serviriam ao nosso propósito:

\section{Charadas com nomes de celebridades \\ P.: Você já viu esta roupa aqui? \\ R.: O Clodovil. \\ P.: 0 seu cachorro late muito? \\ R.: 0 do Fausto Silva.}

\section{Piadas com nomes e profissões}

Passos Dias Aguiar taxista

$\begin{array}{ll}\text { H. Lopes } & \text { professor de hipismo } \\ \text { Décio Machado } & \text { guarda florestal } \\ \text { P. Lúcia } & \text { fabricante de brinquedos } \\ \text { Inácio Filho } & \text { obstetra } \\ \text { Olavo Pires } & \text { balconista de bar }\end{array}$

Veremos que nesses dois casos a compreensão das piadas depende de um procedimento de leitura comparável ao que ocorre acidentalmente na fábula de Monteiro Lobato e, o que é mais importante, uma compreensão razoavelmente explícita da ambiguidade. Assim, para que as piadas funcionem, é preciso apreender a homofonia entre o nome Clodovil e uma oração possível em que o segmento final seria o verbo viu ou entre o nome Silva e uma forma flexional do verbo silvar e assim por diante. A leitura do trocadilho é, pois, uma leitura que lida com segmentações e interpretações morfossintáticas paralelas, mas diferentemente do que ocorre no erro de leitura, a sobreposição de dois enunciados em um só não é apenas parte constitutiva do texto, mas o elemento por meio do qual este realiza seu propósito genérico e pragmático - o de causar o riso.

Há muitas possibilidades de trabalho com piadas em sala de aula - poderíamos pedir aos alunos que coletem piadas em programas de televisão, que aprendam piadas com parentes e amigos para contá-las e analisá-las em sala de aula, que observem ao longo de um período de tempo ocorrências de chistes e "tiradas" semelhantes em conversações na rua, na escola, em casa etc. Seria possível analisar o desempenho de humoristas e contadores de piadas para realizar experiências semelhantes na escola ou contrapor o chiste e o trocadilho a outras formas de humor (o escárnio ou degradação mútua dos interlocutores; o uso de termos chulos e seus substitutos metafóricos; os bordões de certas personagens de humor, que lidam com a constante ressignificação de uma mesma frase em situações diferentes; a imitação; o susto etc.).

2. Vale a pena remeter ao trabalho de Possenti (1998) e, é claro, ao de Freud (1905). 
Seja como for que o trabalho se desenvolva dai pela frente, um efeito importante dessas atividades é o de dar consequência ao discurso do aluno, inclusive quando ele erra, mas não apenas por essa razão. Trata-se de confrontá-lo com o fato de a sua resposta não ser a que o professor esperava - o que é o mínimo necessário -, mas também com o fato de haver alguém à escuta, pronto para reconhecer seus movimentos na linguagem. Nesse sentido, aliás, pouco importa se esses movimentos são bem ou mal-intencionados porque, ao fim e ao cabo, a intervenção do professor não se situa na dicotomia entre louvar ou repreender. Recusar-se a cair no embuste da "rataria" sem, no entanto, ressentir-se de uma suposta traição, é uma forma de construir um lugar específico como interlocutor do aluno, que talvez possamos considerar como sendo o papel que caberia mais propriamente ao professor de língua - o de responder ao aluno, sempre, desde essa posição em que ele não se permite vivenciar os prazeres e as agruras da palavra alheia senão como ponto de partida para lançar o aluno a uma constante reflexão sobre a linguagem e elaboração de sua posição como sujeito falante, titular de uma palavra na qual, cada vez mais, se espera ver o retrato de uma singularidade.

Com isso, o professor não está apenas preservando a seriedade de sua imagem, como também lançando o discurso do aluno para um campo de realidade, isto é, para o território de vigência de um recalque ${ }^{3}$ no qual a relação entre dois sujeitos precisa ser pontuada por alguns cortes que não permitam aos dois se evitarem indefinidamente num jogo de evasivas. Nesse sentido, leituras como a da "rataria" de Monteiro Lobato talvez prestem testemunho de um sintoma que vem se instaurando de maneira preocupante no ensino - a evitação da palavra do outro, seja na forma do aluno que evita o texto e encontra maneiras de, lendo-o, não o ler; seja na forma do professor que evita a discursivi-dade do aluno, ancorando-se na segurança de um normativismo dogmático, hierárquico, nos moldes da gramática que se tem criticado nas últimas décadas. Se hoje, no entanto, situamo-nos sob os efeitos de uma herança socio-interacionista, não é demais se lembrar daquilo que constitui o discurso do professor - o fato de que, como discurso, ele não é palavra solitária, mas necessita de uma outra palavra para realizar-se, ela mesma, como um discurso. Em suma: todo discurso porta em seu interior a falta do discurso do outro. Para aqueles que ousam se pôr à frente de uma sala de aula em tempos que vêm sendo implacáveis com a escola, talvez o maior desafio, então, seja o de abrirse, como sujeitos, para aquilo que precisarão encontrar em si mesmos, mas que só poderá vir por meio de uma outra subjetividade - esta enigmática alma do aluno contemporâneo.

Está posto um grande problema para a formação do professor de língua: mais do que nunca, as circunstâncias de sua profissão o impedem de nutrir, por longo tempo, uma relação pacífica com seu conhecimento. Entrar em sala pede, a todo instante, uma definitiva tomada de atitude.

3. Falar em "recalque" é remeter a questão da linguagem ao terreno da Psicanálise. A esse respeito, ver, por exemplo, a oposição de Lacan (1998) entre "fala vazia" e "fala plena". 


\section{Referências bibliográficas}

ABAURRE, M. B. M.; FIAD, R. S.; MAYRINK-SABINSON, M. L. T. Cenas de aquisição da escrita: o sujeito e o trabalho com o texto. Campinas: Associação de Leitura do Brasil; Mercado de Letras, 1997.

BELINTANE, C. Leitura e alfabetização no Brasil: uma busca para além da polarização. Educação e Pesquisa, v. 32, n. 2, maio/ago 2006.

CALIL, E. Escutar o invisível: escrita e poesia na sala de aula. São Paulo; Rio de Janeiro: UNESP; Funarte, 2008.

CERTEAU, M. de. A invenção do cotidiano: I. artes de fazer. Tradução de Ephraim Ferreira Alves. Petrópolis: Vozes, 1994.

CUNHA, C.; CINTRA, L. F. L. Nova gramática do português contemporâneo. 2. ed. Rio de Janeiro: Nova Fronteira, 1985.

FREUD, S. 0 chiste e sua relação com o inconsciente. Rio de Janeiro: Imago, 1905.

LACAN, J. Função e campo da fala e da linguagem em psicanálise. Escritos. Tradução de Vera Ribeiro. Rio de Janeiro: Jorge Zahar, 1998, p. 238-324.

MORTATTI, M. do R. L. Cartilha de alfabetização e cultura escolar: um pacto secular. Cadernos CEDES, ano XIX, n. 52, nov./2000.

POSSENTI, S. Discurso, estilo e subjetividade. São Paulo: Martins Fontes, 1988.

Os humores da língua: análises linguísticas de piadas. Campinas: Mercado de Letras, 1998.

. A leitura errada existe. In: BARZOTTO, V. H. (Org.). Estado de leitura. Campinas: Mercado de Letras/Associação de Leitura do Brasil. Coleção Leituras no Brasil, 1999.

Sobre o ensino de português na escola. In: GERALDI, J. W. (Org.). 0 texto na sala de aula. São Paulo: Ática, 2004, p. 32-38.

RODARI, G. Gramática da fantasia. Tradução de Antônio Negrini. São Paulo: Summus. 1982.

Recebido em 30.10 .08

Aprovado em 07.07.09

Thomas Massao Fairchild, graduado em Letras-Português, doutor em Educação pela Universidade de São Paulo, é professor do Instituto de Letras e Comunicação da Universidade Federal do Pará e pesquisador do Grupo de Estudos e Pesquisa Produção Escrita e Psicanálise (GEPPEP). 